Article

\title{
German Marathon Runners' Opinions on and Willingness to Pay for Environmental Sustainability
}

\author{
Thomas Könecke ${ }^{1,2,3, * \mathbb{D}}$, Holger Schunk ${ }^{3,4}$, Tabea Schappel ${ }^{5}$, Ine Hugaerts ${ }^{1}$, Fabio Wagner ${ }^{5}(\mathbb{D}$ \\ and Ewa Malchrowicz-Mośko ${ }^{6}$ (D) \\ 1 Policy in Sports \& Physical Activity Research Group, KU Leuven, 3001 Leuven, Belgium; \\ ine.hugaerts@kuleuven.be \\ 2 ICERIS (Interdisciplinary Centre for Ethics, Regulation and Integrity in Sport), KU Leuven, \\ 3001 Leuven, Belgium \\ 3 Research Group Management and Entrepreneurship in Media and Sport, 65022 Wiesbaden, Germany; \\ holger.schunk@hs-rm.de \\ 4 RheinMain University of Applied Sciences, 65022 Wiesbaden, Germany \\ 5 Department of Sport Economics, Sport Sociology and Sport History, Johannes Gutenberg-University Mainz, \\ 55128 Mainz, Germany; t.schappel@web.de (T.S.); wagnerfa@uni-mainz.de (F.W.) \\ 6 Department of Sports Tourism, Institute of Sport Sciences, Poznan University of Physical Education, \\ 61-871 Poznan, Poland; malchrowicz@awf.poznan.pl \\ * Correspondence: thomas.koenecke@kuleuven.be; Tel.: +32-16-19-33-38
}

check for

updates

Citation: Könecke, T.; Schunk, H.; Schappel, T.; Hugaerts, I.; Wagner, F.; Malchrowicz-Mośko, E. German

Marathon Runners' Opinions on and Willingness to Pay for Environmental Sustainability. Sustainability 2021, 13, 10337. https://doi.org/10.3390/ su131810337

Academic Editor: Emilio Villa-González

Received: 12 June 2021

Accepted: 4 September 2021

Published: 16 September 2021

Publisher's Note: MDPI stays neutral with regard to jurisdictional claims in published maps and institutional affiliations.

Copyright: (c) 2021 by the authors. Licensee MDPI, Basel, Switzerland. This article is an open access article distributed under the terms and conditions of the Creative Commons Attribution (CC BY) license (https:/ / creativecommons.org/licenses/by/ $4.0 /)$.

\begin{abstract}
Research on sustainability and/in sport and, specifically, on the ecological aspects of participatory sporting events is still very scarce despite the recognition these topics have received by actors like, for instance, the European Commission and the United Nations. Against this backdrop, this paper sheds light on a field that is virtually uncharted in academic research, which is the environmental attitudes and willingness to pay for environmental sustainability of participants in participatory sporting events in Europe. In collaboration with the organizer of the Frankfurt Marathon, a study was conducted with a specific focus on German (speaking) marathon runners. In total 1764 data sets were collected with a German (1455 respondents) and an English (309 respondents) online questionnaire. Very insightful descriptive analyses showed that the awareness for the issue of sustainability and sport is still low and that ecological initiatives only have a medium influence on the evaluation of a marathon event. Nevertheless, particularly the German-speaking respondents indicated a high willingness to pay for environmental sustainability in general and for specific measures that can enhance the environmental friendliness of a marathon event, in particular. As will be discussed in the paper, these insights have important managerial implications and are a valuable basis for further research in this evolving field.
\end{abstract}

Keywords: marathon; running; ecology; environment; pro-ecological attitudes; Frankfurt Marathon; Europe; Germany; willingness to pay

\section{Introduction}

The publication of the United Nation's Sustainability Development Goals in 2015 was an important step for the sport sector because it was the first time that an international policy organization specifically mentioned sport as a relevant enabler of sustainable development [1,2]. Already, in 2007, the European Commission had addressed that sport-event organizers should make events more sustainable [3], which seemed advisable as sporting events can have a significant environmental impact [4-7]. Accordingly, it is not a surprise that environmental sustainability has been researched in the context of sport mega-events to a certain extent [8-10]. Yet, to date, research on environmental sustainability in the sports sector is underdeveloped and only some examples can be found particularly for smaller sporting events or participatory sport [11-19]. 
This scarcity is problematic for a number of reasons. First of all, events that are small in scale are much more common than events of international magnitude [18,20,21]. Moreover, many sports can be very harmful to the environment (for instance, due to artificially irrigated golf courses in drought regions, artificial-snow-covered ski slopes, etc.) [22,23]. And even though some sports do not necessarily harm the environment per se-such as cycling or running [24] — the steady increase in mass sporting events around the world and corresponding event tourism can obviously be problematic [25], for instance due to greenhouse gas emissions [26].

On the other hand, athletes can enjoy practicing sport in natural environments while taking care of their own body and health. If it is not the case from the start, practicing sport in natural settings can lead to an increased concern for the environment and the realization that runners and other active sportspeople might contribute to its destruction with their activities. As marathons, for instance, often take place in nature-based settings, marathon runners may show considerable concern for the nature they run in, as they can directly link it to health benefits they experience [27]. Against this backdrop, Davies et al. compared the runners' concern for the environment with participation motives in an urban and rural marathon [28]. Other studies also suggest that (extreme) sport participation (e.g., running ultramarathons) cultivates a strong connection with nature and the natural environment $[29,30]$.

Today, sports organizations often try to contribute to the promotion of environmentally friendly behavior of sports consumers and use sporting events as platforms for interventions [31,32]. However, only a small body of research has investigated pro-ecological intentions specific to the sport context thus far and the relationship between athletes and ecological issues is still debatable $[33,34]$. Of specific interest, here, is the question of whether participants in sporting events are willing to contribute financially to enhance the ecological footprint of their activities. In this regard, some research has been conducted, but overall, this field is still in its infancy. Specifically, Krugell and Saayman (2013) and Saayman, Krugell and Saamyman (2016) have analyzed the willingness to pay for environmental measures in a marathon and a cycling race in South Africa [35,36].

Against this backdrop, the research presented in this paper aims at shedding some light on the environmental attitudes of marathon runners in Germany. To make this initial research possible, a collaboration was initiated with the organizer of the Frankfurt Marathon, one of the largest running events in Germany. This collaboration gave the researchers a one-time opportunity to include a link in a newsletter that led to a short online questionnaire. This newsletter is regularly sent out to over 40,000 recipients, most of whom have participated in the Frankfurt Marathon in the past. The questionnaire was provided in German and English because approx. 20\% of the recipients of the newsletter receive an English version. Predictably, these recipients almost exclusively live outside of Germany. On the other hand, it is to be expected that almost all of the recipients of the newsletter in German are from Germany and only a very small percentage from the much smaller German-speaking populations in neighboring countries (mainly Austria and Switzerland). Accordingly, the descriptive analyses outlined in this paper have been conducted for three groups: the overall sample, as well as the subsamples that filled in the German and the English version of the questionnaire. The idea behind the comparison between the two subsamples is to very specifically look into German marathon runners' environmental attitudes and to use the non-German-speaking runners as a control group for comparison.

This first study is a basis upon which a series of empirical studies revolving around the topics pro-environmental attitudes and willingness to pay for environmental friendliness in sport contexts in Europe will be built. Considering that environmental attitudes and general willingness to pay of marathon runners in Germany is a totally unmapped field in academia, it was decided to focus on a descriptive analyses of four key questions from the survey. These descriptive analyses yield a number of interesting insights of high practical and academic relevance why it was decided to publish them without applying further 
more sophisticated analyses. Otherwise, it would have been difficult to put a sufficient amount of focus on the compelling story that a look at the basic data already tells. Apart from academic interest, this research is motivated by the hope to make event managers aware of opportunities to further and finance an improvement of the eco-friendliness of their participatory sporting events.

The specific focus of this paper is represented by four questions that could be included in the survey as the answers were also of interest to the organizers of the Frankfurt Marathon. First of all, the general environmental attitudes of the marathon runners were assessed with two questions. The remaining two questions were specifically motivated by past research conducted in Germany without specific focus on the sport sector or active sport participants $[37,38]$ and in South Africa in a sport context $[35,36]$. They were of particular interest because no specific data on the willingness to pay for environmental sustainability was available for the European context in general or Germany as the biggest European economy in particular even though large numbers of running events usually are staged there every year (unless, of course, a pandemic strikes). The third question was geared towards capturing the willingness to pay for environmental friendliness in the purchasing process in general. The fourth question inquired for which marathon-specific factors the respondents would be willing to pay an increased participation fee. When deciding which factors to include in the multiple-choice list, three factors that can help to enhance the environmental friendliness of a running event were included (organic products, waste separation and management, decreased use of plastic).

The structure of this paper is as follows: The next chapter (Materials and Methods) contains three sub-chapters. First, the Frankfurt Marathon will briefly be described as it is the common link for the survey participants because almost all of them have participated in the past and all of them are very interested in the event (otherwise they would not have signed up for the newsletter). Next, the data collection including the relevant questions of the survey will be outlined. Third, the overall and the two subsamples will be characterized based on certain socio-demographic and event-related information the respondents have provided. In the following chapter the results are described based on the four questions mentioned above. Afterwards, a discussion follows. In the final chapter, key conclusions are provided and future research that can build on the insights presented in this paper are outlined.

\section{Materials and Methods}

\subsection{The Event: Mainova Frankfurt Marathon}

The annual marathons in Frankfurt (Frankfurt Marathon) have continuously been organized under differing names since 1981. The last edition of the event that was staged before this research was conducted was the 2019-edition. It was then called "Mainova Frankfurt Marathon" with Mainova, a regional energy supplier, as the main sponsor. Based on finishers, the event was the second largest marathon in Germany that year with 10,561 finishers [39].

The organization staging the marathon, motion events, is very eager to improve the environmental friendliness of the Frankfurt Marathon. By 2005, the first investments had already been made into making the event more environmentally sustainable. Since then, it has been the explicit aim to become "greener every year" [40]. One example of specific steps that have been taken in this direction is that the T-shirts for runners and volunteers are now made of $100 \%$ recycled polyester. Moreover, cars used during the race are usually powered by electronic engines, and organic food is offered to the runners during and after the race, and to the spectators as well. Free commutation by public transportation within the Rhein-Main-Area is also available to all participants and carpooling is encouraged if travel by car is considered inevitable.

As an outcome of these efforts, the Frankfurt Marathon won the AIMS Green Award which is awarded by the Association of International Marathons and Distance Races in 2014 when it was called "BMW Frankfurt Marathon", as BMW was the main sponsor [41]. 
Another result of this commitment to environmental sustainability is the consideration as best practice by the German Federal Ministry for the Environment and the German Olympic Sports Confederation (Deutscher Olympischer Sportbund) [40].

\subsection{Data Collection}

In collaboration with the event organizer, a survey was conducted just before the COVID-19 pandemic hit Europe between 28 January and 5 February 2020, using the online survey software Unipark. A link to the survey was included in a newsletter, of which a German and an English version are regularly sent to subscribers interested in the Frankfurt Marathon. In total, 32,003 people received the German and 8010 the English newsletter containing the link to the questionnaire, which was provided in both languages as well. Overall, the survey was accessed 2251 times (1812 times in German and 439 times in English) and 1764 respondents finished answering the questionnaire (1455 in German and 309 in English). It did not seem feasible to calculate a response rate because it could not be determined how many of the email accounts to which the newsletter was addressed were still active or how many of the recipients opened the newsletter. The questions relevant for this study were answered by almost all participants who finished the questionnaire. The survey data was handled and analyzed using SPSS and MS Excel.

As the questionnaire was developed in cooperation with the organizers of the Frankfurt Marathon, the amount and detailedness of the questions that could be included was limited. Overall, 18 questions were asked in the survey. The study presented in this paper is based on four of those questions. The reasons for including each of these four questions is explained hereafter.

As mentioned in the introduction, sport has been identified as a field that can substantially contribute to environmental sustainability by key opinion-builders like the UN [1]. Moreover, the general awareness that sport might be a valuable contributor to a more sustainable future has steadily been increasing [42]. Nevertheless, very little is known about how actively sports participants think about ecological issues and whether they consider this a relevant topic at all $[33,34]$. This gap in research is of particular relevance because of the large number of participatory sporting events, as referenced in the introduction, as well and the very large number of people participating in these events. It is also very relevant for this research that the Frankfurt Marathon is openly committed to becoming "greener every year" (see above). This is why the organizers of the event were so interested in learning whether environmental sustainability in sport is a relevant topic to the survey participants or not. Accordingly, the following question was asked: "How intensively have you personally dealt with the issue of sustainability in sport?" To answer this question, a five-point-scale was offered in which one was defined as "not at all" and five as "very intensively".

From an academic, but also from a practical perspective, it is important to understand which main factors influence marathon runners' positive perception of a running event. Accordingly, it was agreed to include the following question in the survey: "How strongly do the following factors influence your positive assessment of a marathon event?" To answer the question, a choice was to be made from a list of options (more than one option could be indicated). Due to the pro-ecological ambitions linked to the event and because of the research interest of this study, it was agreed to include the following item as one of the answer options "Ecological measures at the event".

The final two questions that were included in the questionnaire, specifically for this study, aimed at the willingness to pay for environmental sustainability, in general, and in terms of a marathon event, specifically. The first of these questions inquired about the general willingness to pay for environmentally friendly products. It was based on previous research that had been conducted in Germany. This previous study was comprised of a very large sample that was representative of the German population. Using conjoint and a cluster analyses, it showed that approximately one third of the respondents had a higher willingness to pay if products were environmentally friendly [37]. For the study presented 
in this paper, the following question was asked: "If you consider buying an environmentally friendly product, which statement describes you best?" The respondents could answer the question by selecting one of seven statements to describe their preference.

The final question included in the survey specifically for this research was "For which factors would you be willing to pay an increased participation fee?" Obviously, this question relates to the one just described and is based on the study conducted by Bauer and Schunk (2016) that showed that environmental friendliness was an important factor in the buying decision of German customers [38]; but this study neither identified specific information for sports contexts nor for active sports participants. Accordingly, a question was included with the aim of specifically assessing the general willingness to pay for environmental friendliness in the context of a marathon event. Again, multiple answers could be chosen from a list. Apart from other response items, the following ones were included specifically for this study:

- Only organic products

- Optimized waste separation and waste management

- Decreased use of plastic due to use of sustainable alternatives

Moreover, a limited amount of sociodemographic data was collected from the questionnaire. Since it had been agreed with the organizer of the event that only a very limited number of questions regarding personal information could be recorded and that full anonymity would have to be guaranteed at any cost, only rather general data, on education, age and gender, was collected. Agreement was reached to include a question pertaining to levels of education, because past research in Germany has shown that a higher educational level may be associated with a higher concern for ecological sustainability [43,44]. Age (in categories ranging from "18-25 years" to "over 66 years") and gender were included, as well, to get a general understanding of the representativeness of the sample, which was also of interest for the event organizer. Event-related variables (e.g., on past participation) were also included, some of which were used in this study to better understand the connectedness of the respondents to the Frankfurt Marathon.

\subsection{Description of the Overall Sample and the Two Subsamples}

As has been mentioned above, 1764 respondents finished answering the questionnaire (1455 the one in German and 309 the English one) and were included in the analyses. All data sets were rather complete and of high quality, which led to the conclusion that the survey participants were highly motivated to give their opinion. In total, 403 respondents indicated that they were female $(23.0 \%), 1338$ respondents they were male $(76.4 \%)$, while 11 chose not to answer this question or to indicate "no answer" $(0.6 \%)$. Of the Germanspeaking (GS) respondents, $74.6 \%$ were male and $23.9 \%$ female, whereas the corresponding figures for the English-speaking (ES) respondents were $81.6 \%$ and $17.8 \%$, respectively. The event organizer provided the information that over the last five years, roughly two thirds of the participants were male and one third female runners. This means that, in the overall sample, as well as in the two subsamples (GS and ES), females were somewhat underrepresented if compared to the marathon participants of this period.

On average, the respondents indicated to have participate in two large mass running events per year, defined as having at least 10,000 visitors or 5000 participants. A vast majority of the survey participants has already participated in the Frankfurt Marathon $(96.1 \%)$. More specifically, $41.2 \%$ of the respondents had participated once, $23.4 \%$ twice, $11.3 \%$ three times, $5.3 \%$ four times and $14.9 \%$ more than four times. A further $59.7 \%$ of the respondents had participated in the last episode of the event, in 2019, before the data for this study was collected in early 2020.

The age of the participants was asked categorically (Table 1). Based on this categorization, the age groups of $36-45$ and $46-55$ years made up $63.4 \%$ of the sample. For the GS and the ES subsamples the figures were $62.3 \%$ and $68.9 \%$, respectively. All of these figures are roughly in line with the information provided by the event organizer for the five previous 
races because the majority of participants in recent years has been between 40 and 55 years of age.

Table 1. Distribution of the respondents' age groups $(n=1764)$.

\begin{tabular}{ccccccc}
\hline & \multicolumn{2}{c}{ Total Sample } & \multicolumn{2}{c}{ German-Speaking Runners } & \multicolumn{2}{c}{ English-Speaking Runners } \\
\hline Age Group & Respondents & Percent & Respondents & Percent & Respondents & Percent \\
\hline $18-25$ years & 30 & $1.7 \%$ & 29 & $2.0 \%$ & 1 & $0.3 \%$ \\
\hline $26-35$ years & 193 & $10.9 \%$ & 138 & $9.5 \%$ & 55 & $17.8 \%$ \\
\hline $36-45$ years & 487 & $27.6 \%$ & 368 & $25.3 \%$ & 119 & $38.5 \%$ \\
\hline $46-55$ years & 632 & $35.8 \%$ & 538 & $37.0 \%$ & 94 & $30.4 \%$ \\
\hline $56-65$ years & 344 & $19.5 \%$ & 308 & $21.2 \%$ & 36 & $11.7 \%$ \\
\hline $66+$ years & 72 & $4.1 \%$ & 68 & $4.7 \%$ & 4 & $1.3 \%$ \\
\hline No answer & 6 & $0.3 \%$ & 6 & $0.4 \%$ & 0 & $0.0 \%$ \\
\hline Totals & 1764 & $100 \%$ & 1455 & $100 \%$ & 309 & $100 \%$ \\
\hline
\end{tabular}

As it is not uncommon for long-distance runners in Europe (e.g., in Poland [45]), the majority of the respondents has obtained at least a high school diploma, allowing them to attend a university $(80.4 \%$ of the total sample, $75.8 \%$ of the GS and even $94.2 \%$ of the ES subsample). As can be seen in Table 2, less than one fifth of the participants who answered this question had not attained this educational level in the overall sample. The figures for the two subsamples were $22.4 \%$ for the GS and only $4.8 \%$ for the ES one.

Table 2. Categorized educational level of the respondents $(n=1764)$.

\begin{tabular}{|c|c|c|c|c|c|c|}
\hline \multirow[b]{2}{*}{ Educational Background } & \multicolumn{2}{|c|}{ Total Sample } & \multicolumn{2}{|c|}{ German-Speaking Runners } & \multicolumn{2}{|c|}{ English-Speaking Runners } \\
\hline & Respondents & Percent & Respondents & Percent & Respondents & Percent \\
\hline $\begin{array}{l}\text { No degree, left school without } \\
\text { formal certificate or before } \\
10 \text { years of schooling }\end{array}$ & 60 & $3.4 \%$ & 59 & $4.1 \%$ & 1 & $0.3 \%$ \\
\hline $\begin{array}{l}\text { Successfully finished } \\
\text { secondary school } \\
\text { (10 years of schooling) }\end{array}$ & 280 & $15.9 \%$ & 266 & $18.3 \%$ & 14 & $4.5 \%$ \\
\hline $\begin{array}{l}\text { High school diploma or } \\
\text { academic degree }\end{array}$ & 1394 & $79.0 \%$ & 1103 & $75.8 \%$ & 291 & $94.2 \%$ \\
\hline No answer & 30 & $1.7 \%$ & 27 & $1.9 \%$ & 3 & $1.0 \%$ \\
\hline Totals & 1764 & $100 \%$ & 1455 & $100 \%$ & 309 & $100 \%$ \\
\hline
\end{tabular}

Summing up, the sample consists of runners who have experience with the Frankfurt Marathon, of which almost $55 \%$ had at least started the race more than once and most of which had participated rather recently. Overall, the respondents were well-educated and mainly belong to the dominant age group among event participants in recent years. Overall, the full sample seems to be a reasonable representation of participants in the Frankfurt Marathon between 2015 and 2019, but it may be relevant that the percentage of female survey participants is comparably low. Even though there were some differences between the two subsamples, it can be expected that those differences should not be sufficiently atypical to distort the results. This assumption is made because, for instance, a higher educational level is to be expected from a majority of the people who go abroad to participate in a marathon. Accordingly, it cannot surprise that the ES subsample has a higher educational level as compared with GS. 


\section{Results}

In each of the following analyses of the answers to the questions outlined above, a look will first be taken at the full sample before the German and English subsamples are scrutinized separately.

\subsection{Question 1: How Intensively Have You Personally Dealt with the Issue of Sustainability in Sport?}

The respondents were asked to rate how intensively they have dealt with the issue of sustainability in sport using a 5-point Likert scale ( $1=$ not at all, $5=$ very intensively). Due to the context in which the question was asked, it was clear that environmental sustainability was referred to and not sustainability's other two dimensions (social and economic sustainability). An average value of 2.86 ( $\mathrm{SD}=1.08$ ) was obtained for the full sample (Table 3). This is slightly below the numerical average of 3.0. The figures for the respondents to the German and the English questionnaire were $2.84(\mathrm{SD}=1.04)$ and 2.96 $(\mathrm{SD}=1.22)$, respectively. When a t-test was conducted, the difference between the two subsamples proved significant at the $5 \%$-level $(t(1462)=1.73)$.

Table 3. Overview over the answers to the question "How intensively have you personally dealt with the issue of sustainability in sport?".

\begin{tabular}{|c|c|c|c|c|c|c|}
\hline & \multicolumn{2}{|c|}{ Total Sample } & \multicolumn{2}{|c|}{ German-Speaking Runners } & \multicolumn{2}{|c|}{ English-Speaking Runners } \\
\hline & Respondents & Percent & Respondents & Percent & Respondents & Percent \\
\hline $1=$ not at all & 197 & $11.2 \%$ & 152 & $10.4 \%$ & 45 & $14.6 \%$ \\
\hline 2 & 439 & $24.9 \%$ & 377 & $25.9 \%$ & 62 & $20.1 \%$ \\
\hline 3 & 648 & $36.7 \%$ & 552 & $37.9 \%$ & 96 & $31.1 \%$ \\
\hline 4 & 339 & $19.2 \%$ & 274 & $18.8 \%$ & 65 & $21.0 \%$ \\
\hline $\begin{array}{c}5=\text { very } \\
\text { intensively }\end{array}$ & 125 & $7.1 \%$ & 88 & $6.0 \%$ & 37 & $12.0 \%$ \\
\hline No answer & 16 & $0.9 \%$ & 12 & $0.8 \%$ & 4 & $1.3 \%$ \\
\hline Totals & 1764 & $100 \%$ & 1455 & $100 \%$ & 309 & $100 \%$ \\
\hline Average & 2.860411899 & - & 2.83991684 & - & 2.9537705 & - \\
\hline $\begin{array}{l}\text { Standard } \\
\text { deviation }\end{array}$ & 1.078163883 & - & 1.04441251 & - & 1.22065006 & - \\
\hline
\end{tabular}

Regarding the specific responses presented in Table 3, a chi-square test was computed to test if the figures between the two subsamples differed in a statistically significant manner. This was the case and a high significance resulted $\left(X^{2}(4, N=1748)=24.0\right.$, $p=0.0002)$. Overall, only rather low fraction indicated not to have dealt with sustainability in sport at all; $11.2 \%$ in the full sample, and $10.4 \%$ in the GS and $14.6 \%$ in the ES subsamples. Accordingly, over $85 \%$ of the runners had at least been confronted with the issue to some extent, and over $60 \%$ of each of the three different (sub)samples checked values between 3 and 5 (63.0\% for all, $62.8 \%$ for the GS and $64.1 \%$ for the ES respondents). It can thus be stated that (environmental) sustainability in sport is an issue that concerns the respondents to a certainly relevant extent. Yet it must also be noted that only rather low percentages indicated to have dealt with the issue "very intensively" (7.1\%, 6.0\% and $12.0 \%)$ and around $20 \%$ for each group indicted the second-highest value $(19.2 \%, 18.8 \%$ and $21.0 \%)$. The highest response rates of each group could be found for the median value of three $(36.7 \%, 37.9 \%$ and $31.1 \%$, respectively), which means that the topic obviously did not have a particularly high priority for most of the respondents.

3.2. Question 2: How Strongly Do the Following Factors Influence Your Positive Assessment of a Marathon Event?

In a next step, we evaluated how strongly ecological activities influence the respondents' positive assessment of a marathon event in general. On a 1-5 scale (no impact-quite 
large impact), the average value for the whole sample was 2.89 ( $\mathrm{SD}=0.99)$, which was also true for the GS subsample ( $\mathrm{SD}=0.98)$, while ES group had a lower average value of $2.85(\mathrm{SD}=1.06)$. A t-test showed no statistically significant differences between the two subsamples $(t(1462)=0.71)$, which is why no further differentiation will be made regarding this question, though at the overall outcome for the full sample is explored.

As the mentioned values lead us to believe, the influence of ecological measures on the positive assessment of a marathon can only be considered average. Figure 1 shows that, particularly, factors that directly influence the event experience of the participants (including travel to and from the event) ranked higher, such as proximity to the runners' place of residence (3.09), the attractiveness of the city (3.56), the attractiveness of the course (3.91), a great atmosphere during the event (4.04) and good organization (4.33). This means that for a majority of the survey participants, ecological measures are of some relevance in their evaluation of a marathon event, but the listed core features proved considerably more important in their assessments. Nevertheless, ecological measures were evaluated much better than the feature that ranked last, which was the participation of famous or elite runners in the race (1.79) even though event organizers are frequently willing to pay large sums for signing prominent participants or for offering attractive prize money. Other important factors, such as favorable participation fees (2.83), attractive social programs (2.86) or event size (2.92) were rated very similarly to ecological activities.

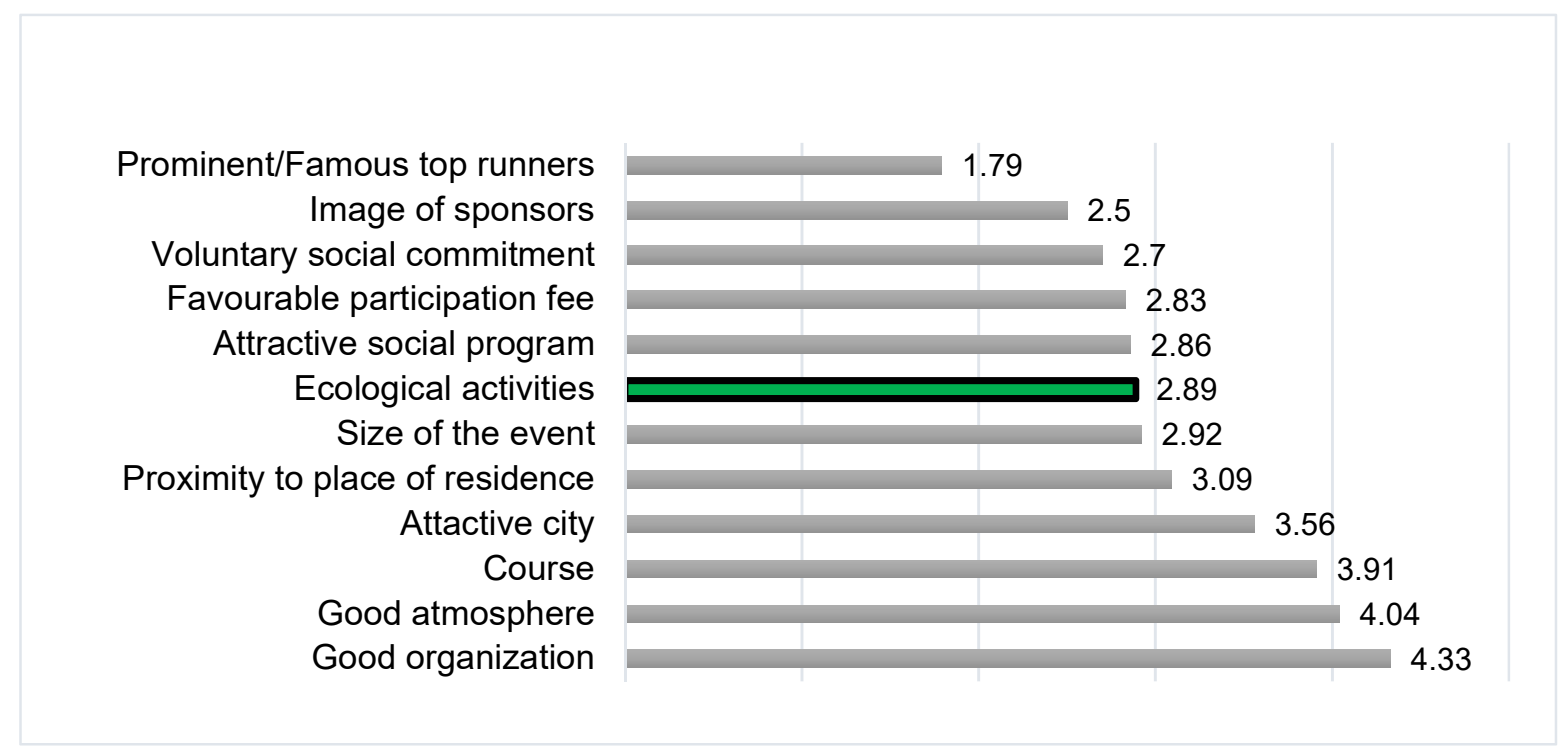

Figure 1. Overview of the answers to the questions "How strongly do the following factors influence your positive assessment of a marathon event?" (scale ranging from 1 (no impact) to 5 (quite large impact)).

\subsection{Question 3: If You Consider Buying Environmentally Friendly Products, Which Statement} Describes You Best?

Next, the question generally inquiring about the preference for buying environmentally friendly products is examined. As can be seen in Table 4, a large part of the overall sample (83.4\%) had a preference for environmentally friendly products. Almost three quarters of the survey participants $(74.7 \%)$ were also willing to pay a little $(46.2 \%)$ or even much more $(28.5 \%)$ for such products.

Considerable differences could be seen between the groups that responded to the survey in German and in English, which was also confirmed by a highly significant chi-square test conducted for the two subsamples $\left(X^{2}(5, N=1576)=36.3, p=0.0000\right)$. Of the German-speaking respondents, $84.9 \%$ preferred and/or bought environmentally friendly products and over three quarters $(77.3 \%)$ were willingly paying more for them. More specifically, nearly half of the respondents $(47.3 \%)$ bought environmentally friendly products if they were a little more expensive than products without this characteristic, 
and $30.0 \%$ claimed this even if such products were considerably more expensive. These figures differ from those in Table 4 for the ES subsample. Here, a total of $76.4 \%$ indicated a preference for environmentally friendly products, but $13.6 \%$ were unwilling to pay for them, leaving a total of $62.8 \%$ who actually paid more for such products, with $41.1 \%$ willing to pay a little and only $21.7 \%$ willing to pay considerably more.

Table 4. Overview over the answers to the question "If you consider buying environmentally friendly products, which statement describes you?".

\begin{tabular}{|c|c|c|c|c|c|c|}
\hline \multirow[b]{2}{*}{ Statements } & \multicolumn{2}{|c|}{ Total Sample } & \multicolumn{2}{|c|}{ German-Speaking Runners } & \multicolumn{2}{|c|}{ English-Speaking Runners } \\
\hline & Respondents & Percent & Respondents & Percent & Respondents & Percent \\
\hline $\begin{array}{l}\text { I don't like environmentally } \\
\text { friendly products. }\end{array}$ & 5 & $0.3 \%$ & 3 & $0.2 \%$ & 2 & $0.6 \%$ \\
\hline $\begin{array}{l}\text { I don't buy environmentally } \\
\text { friendly products. }\end{array}$ & 14 & $0.8 \%$ & 7 & $0.5 \%$ & 7 & $2.3 \%$ \\
\hline $\begin{array}{l}\text { I always buy the } \\
\text { cheapest option. }\end{array}$ & 86 & $4.9 \%$ & 63 & $4.3 \%$ & 23 & $7.4 \%$ \\
\hline $\begin{array}{l}\text { I prefer environmentally } \\
\text { friendly products, but they are } \\
\text { too expensive for me. }\end{array}$ & 153 & $8.7 \%$ & 111 & $7.6 \%$ & 42 & $13.6 \%$ \\
\hline $\begin{array}{l}\text { I buy environmentally friendly } \\
\text { products if they are hardly } \\
\text { more expensive. }\end{array}$ & 815 & $46.2 \%$ & 688 & $47.3 \%$ & 127 & $41.1 \%$ \\
\hline $\begin{array}{c}\text { I buy environmentally friendly } \\
\text { products, even if they are } \\
\text { more expensive. }\end{array}$ & 503 & $28.5 \%$ & 436 & $30.0 \%$ & 67 & $21.7 \%$ \\
\hline No answer. & 188 & $10.7 \%$ & 147 & $10.1 \%$ & 41 & $13.3 \%$ \\
\hline Totals & 1764 & $100 \%$ & 1455 & $100 \%$ & 309 & $100 \%$ \\
\hline
\end{tabular}

\subsection{Question 4: For Which Factors Would You Be Willing to Pay an Increased Participation Fee?}

In question 4 , three of the answers provided concerned measures that enhance a marathon event's ecological sustainability. As can be seen in Figure 2, these three choices all ranked in the top four of all answers to this question (multiple answers were possible). They were optimized waste separation and waste management $(30.7 \%)$, organic-only products $(31.2 \%)$ and decreased use of plastic due to the use of sustainable alternatives $(46.8 \%)$. The second-most selected factor was higher social standards for employees, selected by $33.0 \%$ participants.

As can be seen in Table 5, there were considerable differences in the general willingness to pay for ecology-related factors among the two subsamples. The percentage of the GS speaking respondents that were willing to pay an increased participation fee $(35.0 \%, 33.5 \%$ and $51.1 \%$ ) was consistently higher than that of the ES ones (13.3\%, 17.5\% and $26.9 \%)$.

To obtain a better overall picture, another analysis was conducted regarding this question. It was evaluated which percentages of the overall and the two subsamples had selected how many of the three "ecology-friendly" factors in total. Table 6 shows that $45.8 \%$ of the full sample did not want to pay for any of the environment-friendly factors, whereas $17.4 \%$ indicated a willingness to pay for one of the factors, $19.4 \%$ for two and $17.5 \%$ for three. Again, considerable differences were found between the two subsamples that were statistically highly significant $\left(X^{2}(3, N=1764)=73.2, p=0.0000\right)$. The corresponding percentages were $42.0 \%, 17.1 \%, 20.6 \%$ and $20.4 \%$ for the GS and $64.0 \%, 18.8 \%, 13.6 \%$ and $3.9 \%$ for the ES respondents. This means that the differences between the subsamples were particularly high concerning willingness to pay more for events featuring zero (lower for the GS subsample), two or three factors (higher for the GS subsample). 


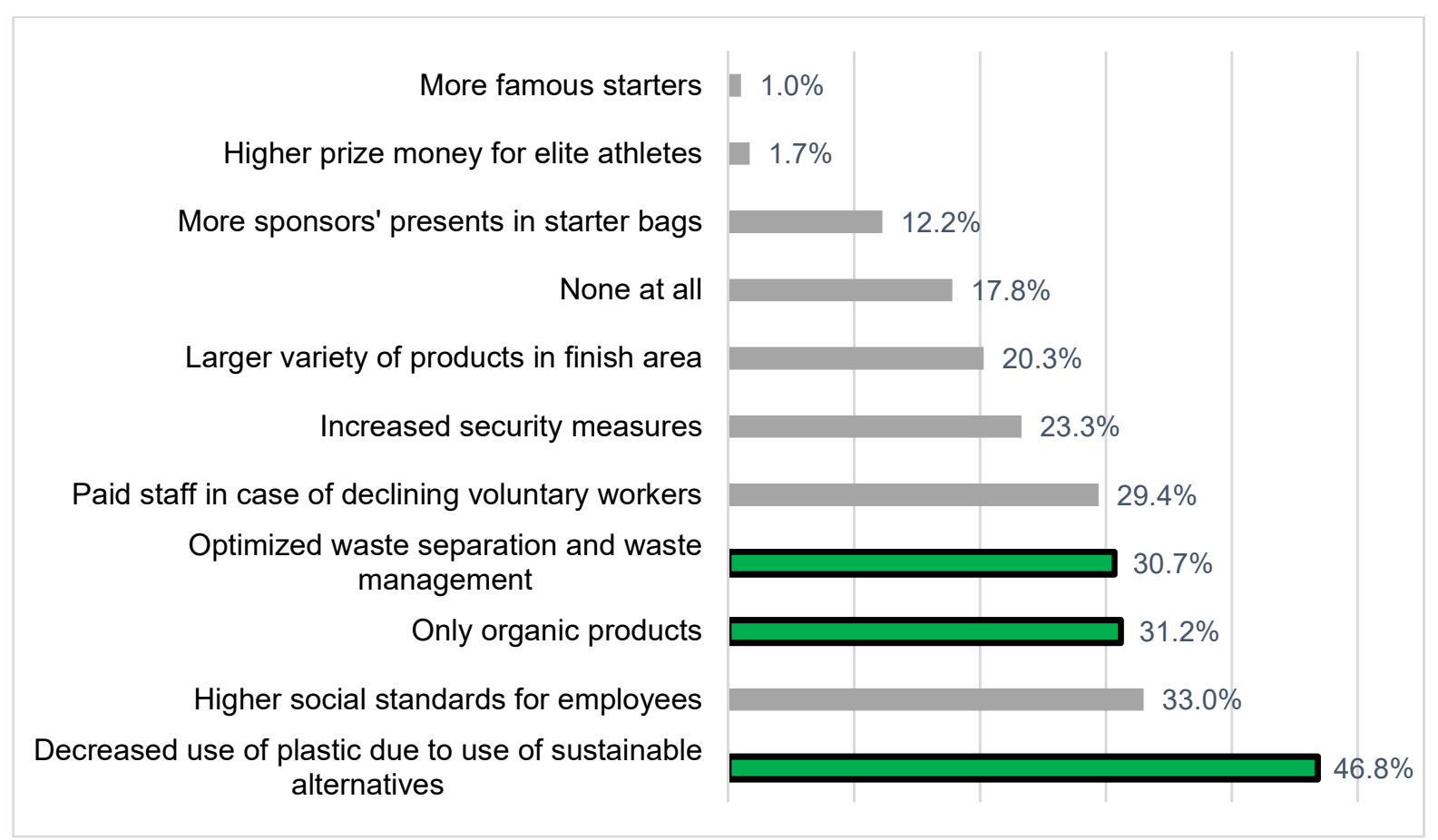

Figure 2. Selection of factors for which survey respondents were willing to pay a higher participation fee (figures in \%, multiple answers possible, $\mathrm{n}=1764)$.

Table 5. Willingness to pay an increased participation fee for different environmentally sustainable factors of a marathon running event (in \%, multiple answers possible, $\mathrm{n}=1764$ ).

\begin{tabular}{ccccccc}
\hline & \multicolumn{2}{c}{ Total Data Set } & \multicolumn{2}{c}{ German-Speaking Respondents } & \multicolumn{2}{c}{ English-Speaking Respondents } \\
\hline Statements & Respondents & Percent & Respondents & Percent & Respondents & Percent \\
\hline Only organic products & 550 & $31.2 \%$ & 509 & $35.0 \%$ & 41 & $13.3 \%$ \\
\hline $\begin{array}{c}\text { Optimized waste separation and } \\
\text { waste management }\end{array}$ & 541 & $30.7 \%$ & 487 & $33.5 \%$ & 54 & 83 \\
\hline $\begin{array}{c}\text { Decreased use of plastic due to } \\
\text { use of sustainable alternatives }\end{array}$ & 826 & $46.8 \%$ & 743 & $51.1 \%$ & $26.9 \%$ \\
\hline
\end{tabular}

Table 6. Total of ecology-friendly factors of a marathon event for which respondents would be willing to pay an increased participation fee (in \%, $\mathrm{n}=1764)$.

\begin{tabular}{ccccccc}
\hline & \multicolumn{2}{c}{ Total Data Set } & German-Speaking Runners & English-Speaking Runners \\
\hline $\begin{array}{c}\text { Number of Ecology-Related } \\
\begin{array}{c}\text { Factors for Which There Was } \\
\text { a Willingness to Pay an } \\
\text { Increased Participation Fee: }\end{array}\end{array}$ & Respondents & Percent & Respondents & Percent & Respondents & Percent \\
\hline 0 & 807 & $45.8 \%$ & 610 & $42.0 \%$ & 197 & $64.0 \%$ \\
\hline 1 & 306 & $17.4 \%$ & 248 & $17.1 \%$ & 58 & $18.8 \%$ \\
\hline 2 & 342 & $19.4 \%$ & 300 & $20.6 \%$ & 42 & $13.6 \%$ \\
\hline 3 & 309 & $17.5 \%$ & 297 & $20.4 \%$ & 12 & $3.9 \%$ \\
\hline Totals & 1764 & $100 \%$ & 1455 & $100 \%$ & 309 & $100 \%$ \\
\hline
\end{tabular}

To further evaluate the differences between the subsamples an overall value was used. It was calculated by averaging the total number of factors chosen by the two subsamples. The average value for the GS subsample was $1.20(\mathrm{SD}=1.19)$ and for the ES one 0.58 $(S D=0.87)$, which turned out to be highly significant $(t(1762)=8.70)$. This means that 
the respondents who had answered the German questionnaire had an average general willingness to pay for more than one of the factors that could make a marathon event more environmentally sustainable. For the ES subsample, this was only true for approximately 0.6 factors.

\section{Discussion}

This chapter starts with the discussion of specific aspects pertaining to each of the four different research questions and will address more general points later on. The order in which the research questions are addressed is the same as in the previous chapter.

Regarding the question "How intensively have you personally dealt with the issue of sustainability in sport?", Table 3 showed that the average values for the full sample $(2.86, \mathrm{SD}=1.08)$, for the GS respondents $(2.84, \mathrm{SD}=1.04)$ and the ES respondents $(2.96$, $\mathrm{SD}=1.22$ ) all were slightly below the numerical average of 3.0. A more detailed analysis of the responses unveiled that only very low percentages of the respondents indicated to have dealt with the issue "very intensively" (7.1\% overall, $6.0 \%$ of the GS and $12.0 \%$ of the ES respondents). Moreover, around one third of respondents indicated the median value as an answer, which, for all groups, was the most selected. These observations lead to the insight that (environmental) sustainability in sport seems to be an issue of some relevance for marathon runners in Germany. Nevertheless, it also has to be noted that it cannot be considered a topic that was dominant in the perception of much of the sample.

Despite the differences shown in Table 3, it can probably be expected that even though there were some statistically significant disparities between the subsamples, they do not seem to be very fundamental. At least to some extent, it can, for instance, be assumed that these differences could be linked to the somewhat higher educational level of the ES subsample or to the fact that these runners had a lower average age. Both these sociodemographic factors should have a positive influence on the concern for environmental matters (also in a sport context). It might also be of relevance that (on average) the ES runners had travelled or were willing to travel farther (some, perhaps, even by airplane) to participate in the Frankfurt Marathon or other running events. For some of the participants, this might lead to a greater concern for their carbon footprint and for the other environmental consequences of their running activities.

The observations made regarding question 1 are in line with the importance that was attributed to ecological activities in the overall assessment of a marathon event in the answers to question 2, which were below the mean value of 3.0 for the full (2.89) as well as both subsamples (2.89 for the GS and 2.85 for the ES respondents), while no statistically significant difference was found between the latter two. Overall, the core features of the event (including travel to and from the event) scored considerably higher than ecological activities, such as the proximity to the runners' place of residence (3.09), the attractiveness of the city (3.56), the attractiveness of the course (3.91), a great atmosphere during the event (4.04) and good organization (4.33). Yet some features were also rated lower, like the presence of famous runners (1.79) or the image of the sponsors (2.50). Considering that a favorable participation fee was evaluated as being almost as important as ecological activities (2.83), and that the size of the event was evaluated only slightly higher (2.92), it can be concluded that ecological measures are not a major factor but are of some importance for marathon runners in Germany.

In terms of the general preference for buying environmentally friendly products, highly significant differences were found between the two subsamples in the answers to question 3. We found that $84.9 \%$ of the GS respondents preferred and/or bought environmentally friendly products and over three quarters $(77.3 \%)$ were willingly paying more for them; $30.0 \%$ even indicated a willingness to pay considerably more in comparison with products without this characteristic. Among the ES respondents, a smaller percentage preferred environmentally sustainable products $(76.4 \%)$, while $62.8 \%$ claimed to pay more for environmentally friendly products, with $21.7 \%$ even willing to pay much more. Despite the group differences, the general willingness to pay for environmentally sustainable 
products was rather high among the respondents. This was especially true for the ones who had answered the questionnaire in German.

These insights lead to the following two considerations: (1) Environmental sustainability seems to be a very important factor in the purchasing decisions of marathon runners in Germany, and particularly the German-speaking ones. This generally is in agreement with past research regarding German customers in general [38] even though a prior study with a different methodology had found that only one third of the German population was actually willing to pay more for eco-friendly product features [37]. Accordingly, a higher percentage of GS marathon runners seemed to show this willingness than is the case for the overall population of the country, but it has to be taken into account that the study here referred to [37] was published in 2016 and that the topic has considerably gained in importance since then. (2) The ES respondents seemed to have a somewhat smaller willingness to pay for environmentally sustainable products than the GS ones. A factor that could be of relevance in this context is that sustainable products could be cheaper in Germany, which is why they might appear more affordable to larger consumer groups. Furthermore, it is possible, that such products are generally more common in Germany, which is why more GS runners buy them or pay-reasonably-more for them; but this can only be assumed, here, and is an interesting avenue for further research.

In question 4, the GS runners showed a significantly higher willingness to contribute financially to the environmental friendliness of a marathon event. From the three relevant multiple-choice answers, the GS group selected an average of 1.2 factors while the ES subsample only chose half as many (0.58). The analyses also showed that $58.0 \%$ of the GS runners were willing to pay for either one, two or all three of these factors, while the same was true for only $36.0 \%$ of the ES comparison group. Very considerable differences could also be found regarding the percentage of people that indicated a willingness to pay for all three factors, which was $20.4 \%$ for the GS and only 3.9\% for the ES respondents. In further analysis of the willingness to pay for the different factors, "only organic products" and "optimized waste separation and waste management" were each selected by one third, and "decreased use of plastic due to use of sustainable alternatives" by over half of the GS runners. For the ES subsample the respective figures were much lower, $13.3 \%$, $17.5 \%$ and $26.9 \%$, respectively. This means that even the ES runners' most-selected factor was clearly exceeded by the least popular factor among the GS runners. Consequently, the slight differences that have been observed between the GS and the ES subsamples in question 3 are much more pronounced in the specific context of a marathon event. Again, this willingness seems to be quite high for the GS respondents if compared to the general population for which studies have been conducted in the past [37,38].

Having discussed the results, the limitations of this study need to be addressed. As has already been outlined above, the percentage of male respondents was rather high with $74.6 \%$ for the GS and $81.6 \%$ for the ES subsamples. It would be interesting to see if higher percentages of female respondents would lead to different outcomes in this type of research, which might be expected based on past research [46]. Moreover, a larger set of socioeconomic and other data could be collected and included in such analyses. In the study presented here, this was not possible due to the limited amount of information that could be collected in the survey.

It has also been mentioned that it did not seem feasible to calculate a response rate for the survey because it could, for instance, not be determined how many of the email accounts that received the newsletter were still active or how many of the recipients opened the newsletter. In terms of the representativeness of the data set, however, the following reasoning was applied: based on information provided by the event organizer for the last five years, it was known that roughly two thirds of the participants were male and one third female runners. This means that in the overall sample as well as in the two subsamples (GS and ES) females were somewhat underrepresented, compared to the participants in the Frankfurt Marathon during the mentioned period. Moreover, data collection via a link, in a newsletter, to an online survey could constitute a selection bias among the 
respondents. However, from the age distribution, such bias does not, at least, seem to have fundamentally affected the representativeness of the population in terms of the age of the respondents, as the sample mainly consisted of the age group that has been dominant among the event participants in recent years (36-55 years). Furthermore, $96.1 \%$ of the respondents had participated in the Frankfurt Marathon before and almost $60 \%$ in the last year before the research was conducted. This means that, apart from the low percentage of females in the sample, the respondents that filled in the survey should not systematically differ from regular participants in the Frankfurt Marathon.

This naturally leads to the question if this sample is also somewhat typical of participants in marathons or other running events in Germany. On average, the respondents indicated to have participated in two large mass running events per year. This means that the preferences they have expressed in the survey should not only be typical of participants in the Frankfurt Marathon. Nevertheless, it could be relevant, in the context of this research, that the event openly promotes environmental initiatives, which should be particularly apparent to recipients of the newsletter. This could have led to a bias when opting to participate in the survey, or even beforehand, when signing up for the newsletter and/or choosing to participate in the Frankfurt Marathon. The latter, of course, seems rather unlikely as the importance of ecological initiatives for the evaluation of the event was not found to be a very relevant factor in this study (cf. question 2).

\section{Conclusions}

By 2007, the environmental sustainability of sporting events had been identified as important by the European Commission [3]. However, to date, research specifically targeted at the ecological aspects of participatory sporting events is generally very scarce, and the relevance environmental issues have for participants in the most popular mass sporting events, particularly in Europe, is a topic that has virtually not been considered in academia. The research presented in this paper is a contribution to filling this void. It was made possible by a collaboration with the organizer of the Frankfurt Marathon, one of the largest marathon events in Germany. By including a link to an online survey in a newsletter that was sent to over 40,000 recipients, 1764 data sets were collected. 1455 respondents filled in the German version of the questionnaire, 309 the English one. In this paper, four questions, included in the survey with the agreement with the event organizer, were analyzed to provide first insights into the attitudes of marathon runners in Germany toward environmental sustainability and their willingness to pay for it. The analyses were conducted for three groups, the overall sample and the German-speaking and English-speaking subsamples with a particular focus on the results of the group that filled in the German questionnaire.

Summing up the results presented in this paper, it can be stated that the issue of sustainability in sport has raised some concern among runners but-and this is even more true of the GS group - it is not one that has received very much attention so far (question 1). A similar picture could be observed regarding the importance of ecological activities for the overall assessment of a marathon event (question 2), which turned out to be average. Core factors of the event experience, like a good organization or the atmosphere, are much more important, but it has to be stressed that ecological activities have an importance that is equal to other factors that are often prioritized by event organizers, such as social programs or participation fees. Moreover, ecological activities were ranked much higher than the presence of famous runners. Considering the very high willingness to pay for ecologically friendly products in general (question 3) and for selected eco-friendly measures at a marathon event (question 4) that was particularly evident in the GS respondents, these insights lead to a number of implications that will be addressed presently.

First of all, some managerial implications can be drawn. Very obviously, a great opportunity for improving the environmental friendliness of marathons - and possibly_running events in Germany is the high willingness to pay to improve their eco-friendliness. Higher participation fees could contribute to financing such measures and should not be prohibitory 
for many runners if it is clearly explained that the additional money will be used to preserve the environment. To a certain extent, ecological activities could also make an event more attractive for runners who have not yet planned to participate, if the more relevant core factors of the event are in line with their preferences as well.

Furthermore, the insights presented in this paper make three more ideas seem feasible: One is to reallocate money that has previously been spent on hiring top runners or on prize money to furthering the ecological sustainability of the event. This should openly be communicated and should-based on the outcome of this research-have a positive effect on the brand image of the event. Another suggestion is to use the insights presented in this paper to approach sponsors for financing specific measures to protect the environment in the event's context, such as the reduction of plastic or its replacement by sustainable alternatives. Moreover, we counsel to not repel frugal or less affluent runners by raising participation fees for ecological measures; the opportunity to make a voluntary contribution to the eco-friendliness of the event could be worth pursuing. This suggestion is also based on research published by Triantafyllidis and Kaplanidou in 2019 [27] and seems to be a good idea for another reason; since the specific amount that the runners would be willing to pay has not been identified in this paper (though it is a topic that will be addressed in follow-up research) it is unclear exactly how much money different types or groups of runners would be willing to pay for specific measures or in general. If the amount of an optional payment could be determined by the runners themselves, it is to be expected that the total outcome could be maximized and that no drop in the participation figures should result that might otherwise occur if contributions were mandatory.

The low percentage of runners who have shown a high interest in the issue of ecological sustainability and sport in question 1 showed that the topic should generally be addressed much more by organizers of marathons, particularly in urban areas. This is so because research that has been done on running events in natural settings has indicated a higher concern for the issue $[27,29,30]$ than has been detected for this sample of runners linked to the second largest city marathon in Germany. These considerations also point at another avenue for further research-determining which differences exist, in terms of ecology-related preferences, between participants in different types of runs and why. Due to the high importance of the issue, it would also be worth assessing how different types of event participants could be motivated to expect or even actively contribute to the improvement of the environmental friendliness of running and other sporting events. Looking at the great dynamic that the topic has developed in recent years, it would furthermore be interesting to see if the results of research that ca no longer be considered current is still applicable today. An example would be the study by Diamantopoulos et al. (2003) that found higher concern for environmental issues in females and in members of higher social rank [46].

To conclude, it can be stated that the research presented in this paper has certainly fulfilled its main aim, which was to get a first general overview of environmental attitudes and preferences, as well as the willingness to pay for environmental sustainability, of marathon runners in Germany. Despite the limitations that have been discussed, this study can be considered a valuable contribution that is based on a solid data set with a good sample size, particularly for the GS subsample. Undoubtedly, further research has to follow as many open questions remain regarding environmental sustainability and participatory running events in Germany and Europe. As has been explained before, this study is a starting point for follow-up research and a hope that accompanies its publication is that considerable further research will follow and build on the findings presented here.

Author Contributions: Conceptualization: T.S., T.K., F.W., H.S.; Methodology: T.S., T.K., H.S.; Software: T.K., H.S.; Formal analysis: T.S., T.K., H.S.; Investigation: T.S., T.K., F.W.; Resources: T.S., T.K., E.M.-M.; Data curation: T.S., T.K., H.S.; Writing-original draft preparation: T.K., T.S., I.H., H.S., E.M.-M.; Writing—review and editing: T.K., H.S., I.H., E.M.-M.; Visualization: T.S., T.K., H.S.; Supervision: T.K., F.W.; Project administration: T.S. All authors have read and agreed to the published version of the manuscript. 
Funding: This research received no external funding.

Conflicts of Interest: The authors declare no conflict of interest.

\section{References}

1. United Nations General Assembly. Transforming our world: The 2030 agenda for sustainable development. In Resolution Adopted by the General Assembly on 25 September 2015, RES/70/1; United Nations: New York, NY, USA, 2015.

2. Lindsey, I.; Darby, P. Sport and the sustainable development goals: Where is the policy coherence? Int. Rev. Sport Sociol. 2019, 54, 793-812. [CrossRef]

3. European Commission. White paper on sport. In Commission of the European Communities, COM (2007) 391 Final; European Commission: Brussels, Belgium, 2007.

4. Brymer, E.; Downey, G.; Gray, T. Extreme sports as a precursor to environmental sustainability. J. Sport Tour. 2009, 14, 2-3. [CrossRef]

5. Andrea, C.; Andrew, F.; Max, M.; Annette, R. Assessing the environmental consequences of major sporting events: The 2003/04 FA cup final. Urban Stud. 2007, 44, 457-476.

6. Dolles, H.; Söderman, S. Addressing ecology and sustainability in mega-sporting events: The 2006 football World cup in germany. J. Manag. Organ. 2010, 16, 587-600. [CrossRef]

7. Paquette, J.; Stevens, J.; Mallen, C. The interpretation of environmental sustainability by the International Olympic Committee and Organizing Committees of the Olympic Games from 1994 to 2008. Sport Soc. 2011, 14, 355-369. [CrossRef]

8. Collins, A.; Flynn, A. Measuring the environmental sustainability of a major sporting event: A case study of the FA Cup Final. Tour. Econ. 2008, 14, 751-768. [CrossRef]

9. Jones, C. Assessing the impact of a major sporting event: The role of environmental accounting. Tour. Econ. 2008, 14, 343-360. [CrossRef]

10. Scheu, A.; Preuß, H.; Könecke, T. The legacy of the Olympic Games: A Review. J. Glob. Sport Manag. 2019, 1-37. [CrossRef]

11. Lopez-Bonilla, J.M.; Reyes-Rodriquez, M.D.C.; Lopez-Bonilla, L.M. The Environmental attitudes and behaviours of european golf tourists. Sustainability 2018, 10, 2214. [CrossRef]

12. Mueller, J.T.; Taff, B.D.; Wimpey, J.; Graefe, A. Small-scale race events in natural areas: Participants' attitudes, beliefs, and global perceptions of leave no trace ethics. J. Outdoor Recreat. Tour. 2018, 23, 8-15. [CrossRef]

13. Sato, M.; Ko, Y.J.; Kellison, T.B.; Harada, M.; Bizen, Y. Do snow-based sport participants intend to purchase products from environmentally friendly companies? J. Glob. Sport Manag. 2017, 2, 3. [CrossRef]

14. Cunningham, G.; McCullough, B.P.; Hohensee, S. Physical activity and climate change attitudes. Clim. Change 2020, 159, 61-74. [CrossRef]

15. Gibson, J.H.; Kaplanidou, K.; Kang, J.S. Small-scale event sport tourism: A case study in sustainable tourism. Sport Manage. Rev. 2012, 15, 160-170. [CrossRef]

16. Jiménez-García, M.; Ruiz-Chico, J.; Peña-Sánchez, R.A.; López-Sánchez, A.J. A bibliometric analysis of sports tourism and sustainability (2002-2019). Sustainability 2020, 12, 2840. [CrossRef]

17. Triantafyllidis, S.; Darvin, L. Mass-participant sporting events and sustainable development: Gender, social bonding, and connectedness to nature as predictors of socially and environmentally responsible behavior intentions. Sustain. Sci. 2021, 16, 239-253. [CrossRef]

18. Stevens, J. Major sporting events and environmental sustainability. In Sport and Environmental Sustainability: Research and Strategic Management, 1st ed.; Dingle, G., Mallen, C., Eds.; Routledge: New York, NY, USA, 2021; pp. 47-85.

19. Hugaerts, I.; Scheerder, J.; Helsen, K.; Corthouts, J.; Thibaut, E.; Könecke, T. Sustainability in participatory sports events: The development of a research instrument and empirical insights. Sustainability 2021, 13, 6034. [CrossRef]

20. Kwiatkowski, G.; Könecke, T. Tourism and recurring sporting events. Event tourists' and regular tourists' profiles and expenditures at the Windsurf World Cup on Sylt. Sport Bus. Manag. Int. J. 2017, 7, 464-482. [CrossRef]

21. Taks, M. Social sustainability of non-mega sporting events in a global world. Eur. J. Sport Soc. 2013, 10, 121-141. [CrossRef]

22. Mallen, C.; Chard, C. A framework for debating the future of environmental sustainability in the sport academy. Sport Manag. Rev. 2011, 14, 424-433. [CrossRef]

23. Malchrowicz-Mośko, E.; Botikova, Z.; Poczta, J. Because we don't want to run in smog: Problems with the sustainable management of sport event tourism in protected areas (a case study of national parks in Poland and Slovakia). Sustainability 2019, 11, 325. [CrossRef]

24. Malchrowicz-Mośko, E.; Młodzik, M.; Leon-Guereno, P.; Adamczewska, K. Male and female motivations for participating in a mass cycling race for amateurs. The skoda bike challenge case study. Sustainability 2019, 11, 6635. [CrossRef]

25. Dosumu, A.; Colbeck, I.; Bragg, R. Greenhouse gas emissions as a result of spectators travelling to football in England. Sci. Rep. 2017, 7, 6986. [CrossRef] [PubMed]

26. Bernard, P.; Chevance, G.; Kingsbury, C.; Baillot, A.; Romain, A.J.; Molinier, V.; Gadais, T.; Dancause, K.N. Climate change, physical activity and sport: A systematic review. SportRxiv 2020,1-19. [CrossRef]

27. Triantafyllidis, S.; Kaplanidou, K. Marathon runners: A fertile market for green donations? J. Glob. Sport Manag. 2019, 1-14. [CrossRef] 
28. Davies, M.; Hungenberg, E.; Aicher, T. The relationship between runner environmental paradigm and their motives to participate in an urban or rural marathon. Int. J. Event Festiv. Manag. 2019, 10. [CrossRef]

29. Cherrington, J.; Black, J.; Tiller, N. Running away from the taskscape: Ultramarathon as dark ecology. Ann. Leis. Res. 2020, 23, 2. [CrossRef]

30. MacIntyre, T.E.; Walkin, A.M.; Beckmann, J.; Calogiuri, J.; Gritzka, S.; Oliver, G.; Donnelly, A.A.; Warrington, G. An exploratory study of extreme sport athletes' nature interactions: From well-being to pro-environmental behavior. Front. Psychol. 2019, 10, 1233. [CrossRef]

31. Babiak, K.; Trendafilova, S. CSR and environmental responsibility: Motives and pressures to adopt green management practices. Corp. Soc. Responsib. Environ. Manag. 2011, 18, 1. [CrossRef]

32. Babiak, K.; Wolfe, R. More than just a game? Corporate social responsibility and Super Bowl XL. Sport Mark. Q. 2006, 15, 4.

33. Inoue, Y. Theoretical Foundations for Understanding Pro-Environmental Behavior in Sport; Casper, J.M., Pfahl, M.E., Eds.; Sport Management and the Natural Environment: Routledge, NY, USA, 2015.

34. Matsui, K. Pro-environmental behavior in sport participants. In Sports Management and Sports Humanities; Kanosue, K., Kogiso, K., Oshimi, D., Harada, M., Eds.; Springer: Tokyo, Japan, 2015. [CrossRef]

35. Krugell, W.; Saayman, M. Running a greener race: Willingness-to-pay evidence from the old mutual two oceans marathon in South Africa. South. Afr. J. Res. Sport 2013, 35, 53-70.

36. Saayman, M.; Krugell, W.; Saayman, A. characterisation of cyclists' willingness to pay for green initiatives at Africa's largest cycle tour. South Afr. J. Econ. Manag. Sci. 2016, 19, 432-447. [CrossRef]

37. Sommer, M. Markenführung bei hessnatur-dem CR „Pure Player“ für Mode und Lebensstil. In CSR und Brand ManagementMarken Nachhaltig Führen; Nickel, A.-K., Kirchhof, O., Eds.; Springer Gabler: Wiesbaden, Germany, 2014; pp. $183-196$.

38. Bauer, L.; Schunk, H. Markenführung und Nachhaltigkeit in der Textilindustrie. Umw. Wirtsch. Forum 2016, 24, 369-382. [CrossRef]

39. Laufmarkt Daten Werden Zu Information. Available online: www.laufmarkt.de/In-Deutsch/Statistiken (accessed on 7 June 2021 ).

40. Mainova Frankfurt Marathon and Its Wayto the "Green Marathon". Available online: www.frankfurt-marathon.com/en/ information/green-marathon/ (accessed on 10 June 2021).

41. Association of International Marathons and Distance Races. Available online: www.aims-worldrunning.org/awards.html\#green (accessed on 10 June 2021).

42. Swatuk, A.L. Add sport and stir? The SDGs and sport-environment-development. In Sport, Development and Environmental Sustainability, 1st ed.; Millington, R., Darnell, S.C., Eds.; Routledge: New York, NY, USA, 2020; pp. 19-34.

43. Clamor, T. Determinanten für nachhaltigen Konsum - Eine empirische Analyse für Deutschland. In Soziale, Ökologische und Ökonomische Dimensionen eines Nachhaltigen Energiekonsums in Wohngebäuden; Zentrum für Europäische Wirtschaftsforschung, Fraunhofer Institut für System und Innovationsforschung, Öko-Institut e.V., DIW Berlin, Universität Sankt Gallen: Mannheim, Germany, 2010. Available online: https://kooperationen.zew.de/fileadmin/user_upload/Redaktion/Seco\%40home/Dateien/ SECO\%40home_Werkstattbericht_4_Determinanten_f\%C3\%BCr_nachhaltigen_Konsum.pdf (accessed on 16 December 2019).

44. Bruttel, O. Nachhaltigkeit als Kriterium für Konsumentscheidungen. Ökol. Wirtsch. Fachz. 2014, 29, 41. [CrossRef]

45. Malchrowicz-Mośko, E.; Poczta, J. Running as a form of therapy. Socio-psychological functions of mass running events for men and women. Int. J. Environ. Res. Public Health 2018, 15, 2262. [CrossRef]

46. Diamantopoulos, A.; Schlegelmilch, B.B.; Sinkovics, R.R.; Bohlen, G.M. Can socio-demographics still play a role in profiling green consumers? A review of the evidence and an empirical investigation. J. Bus. Res. 2003, 56, 6. [CrossRef] 